\title{
AS VISÕES FEMININA E MASCULINA ACERCA DA PARTICIPAÇÃO DE MULHERES E HOMENS NO PLANEJAMENTO FAMILIAR
}

\author{
Clarice Marcolino ${ }^{\dagger}$ \\ Elizabeth Perez Galastro ${ }^{2}$
}

Marcolino C, Galastro EP. As visões feminina e masculina acerca da participação de mulheres e homens no planejamento familiar. Rev Latinoam Enfermagem 2001 maio; 9(3):77-82.

Este artigo analisa os resultados das dissertações de mestrado das autoras. Em uma delas, os sujeitos sociais foram homens, e, na outra, mulheres. Os dois estudos foram qualitativos e utilizaram a abordagem fenomenológica. Ao compararmos os resultados das pesquisas, verificamos temas comuns acerca da participação de homens e mulheres no planejamento familiar, os quais foram analisados sob a perspectiva da categoria gênero. Os resultados apontam para modificações nos papéis que homens e mulheres ocupam em relação à reprodução, sexualidade e vida familiar. Diante dessa nova situação, as autoras sugerem uma reorganização dos serviços de saúde de modo a atender a essas demandas.

UNITERMOS: saúde reprodutiva, planejamento familiar, gênero

\section{MALES' AND FEMALES' VIEWS ON WOMEN'S AND MEN'S PARTICIPATION IN FAMILY PLANNING}

This article analyzes the results of the authors' Master's Theses. In one of them, the social subjects were men and, in the other, they were women. The studies were qualitative and used a phenomenological approach. When the research results were compared, common themes concerning the participation of men and women in family planning were found, which were analyzed from the point of view of gender. The results indicate alterations in the roles of men and women in relation to reproduction, sexuality and family life. Given this new situation, the authors suggest a reorganization of health services in order to meet such demands.

KEY WORDS: reproductive medicine, family planning, sex

\section{LA VISIÓN FEMENINA Y MASCULINA DE LA PARTICIPACIÓN DE MUJERES E HOMBRES EN LA PLANIFICACIÓN FAMILIAR}

Este artículo analiza los resultados de las disertaciones de maestría de las autoras. En una de las disertaciones los sujetos sociales fueron varones y en la otra mujeres. Los estudios, cualitativos y utilizaron el enfoque fenomenológico. Al comparar los resultados de las investigaciones analizadas sobre la perspectiva de la categoría de género, observamos temas comunes sobre la participación de varones y mujeres en la planificación familiar. Los resultados hacen pensar en las modificaciones de los roles que hombres y mujeres ocupan en relación con la reproducción, sexualidad y vida familiar. Ante esta nueva situación las autoras sugieren que se realice una reorganización en los servicios de salud con miras a atender estas demandas.

TÉRMINOS CLAVES: medicina reproductiva, planificación familiar, sexo

\footnotetext{
${ }^{1}$ Mestre em Saúde Pública. Doutoranda em Saúde Pública. Professor Assistente; ${ }^{2}$ Mestre em Enfermagem. Professor Assistente. Departamento de Enfermagem Materno-Infantil e Saúde Pública da Escola de Enfermagem da Universidade Federal de Minas Gerais
} 


\section{INTRODUÇÃO}

$\boldsymbol{A}$ transição da fecundidade no Brasil $^{(1)}$ ocorreu com uma rapidez inédita, chegando a níveis inesperadamente baixos - 2,5 filhos por mulher em 1996. Esse fenômeno tem sido qualificado de rápido, abrupto, intrigante, inesperado, imprevisto, iníquo e perverso. 0 mais intrigante ainda é o fato de a mulher brasileira lidar com a reprodução em um cenário de escassa ou quase nula participação masculina. Tal assertiva pode ser verificada através dos dados estatísticos da Pesquisa Nacional sobre Demografia e Saúde ${ }^{(2)}$, que mostra a seguinte prevalência dos métodos contraceptivos mais usados entre homens unidos, incluindo suas parceiras: esterilização feminina 40,3\%; pílula anticoncepcional 18,7\%; condom 5,2\% e vasectomia $2,4 \%$.

A concepção é o resultado natural do intercurso sexual entre homem e mulher. Partindo dessa premissa, espera-se que a anticoncepção seja um fenômeno, também, por natureza, resultante da conjugação de esforços dos parceiros igualmente envolvidos nessa relação. Entretanto, a cultura patriarcal em que vivemos confinou a mulher no âmbito da maternidade, do lar e das tarefas internas familiares. 0 mundo externo (produtivo) foi considerado de âmbito masculino. Nos países latino-americanos, além da cultura patriarcal, o machismo está presente como forma de dominação do homem sobre a mulher ${ }^{(3)}$.

Há poucos estudos sobre o envolvimento dos homens no controle da reprodução, restrito pela própria biologia humana, já que a mulher é quem engravida e sua fecundidade é mais fácil de ser controlada que a do homem. Esses empecilhos práticos não explicam, entretanto, o papel limitado que os homens desempenham na contracepção.

Embora seja pequeno o número de estudos sobre a participação do homem na contracepção, eles mostram que, por ignorarmos 0 interesse dos homens em planejar suas famílias, a sociedade acaba perpetuando estereótipos sexuais.

Pelas razões apontadas, as autoras elaboraram esse texto reflexivo acerca da participação de homens e de mulheres no planejamento familiar, ancoradas nas visões-de-mundo masculina e feminina, respectivamente.

\section{METODOLOGIA}

0 presente artigo é uma reflexão da intercessão dos resultados de duas pesquisas realizadas pelas autoras ${ }^{(4-5)}$, em uma instituição filantrópica localizada na periferia da cidade de Belo Horizonte - Brasil. Nas duas investigações, o objeto de estudo foi o planejamento familiar, sendo que, em uma delas, os sujeitos sociais foram mulheres e, na outra, homens. Os dois estudos foram qualitativos e utilizaram a abordagem fenomenológica.

Para elaborar este artigo, comparamos as categorias empíricas referentes às visões feminina e masculina sobre planejamento familiar, resultantes de ambos os estudos, que ora passam a ser refletidas sob a perspectiva analítica das relações de gênero ${ }^{(6)}$.

\section{RESULTADOS}

\section{A experiência com os métodos contraceptivos temporários}

Os entrevistados relataram suas experiências com os seguintes métodos:

a) Pílula anticoncepcional - um dos métodos mais conhecidos e usados pelos casais.

As mulheres relatam com freqüência problemas relacionados com o uso da pílula anticoncepcional - os seus efeitos colaterais - os quais afetam sua saúde e a falha do método, o que as têm levado ao abandono desse contraceptivo. Os homens, por sua vez, concordam com as mulheres no que se refere à saúde delas e acrescentam a interferência desses problemas no relacionamento do casal.

Vejamos trechos dos discursos que mostram essa perspectiva: - (...) fiquei 10 anos tomando ele, né. Depois comecei a ter problema de pressão... aí o médico falou comigo: é melhor a senhora parar porque já tem muito tempo, tá tendo problema de pressão, eu aconselho a senhora parar agora, não tomar mais pílula; - (...)falei assim: se a gente bobear no resguardo, é perigoso apanhar depois que passar, né porque eu acho que o outro foi assim, assim que terminou eu achei que $o$ comprimido deu certo e não deu, eu fiquei grávida logo depois, antes da menina inteirar um ano e meio... porque ele(o médico) teimava comigo: a senhora não tomou o remédio direito, mas eu tomava, mas eu tomava, mais parecia que o comprimido não valia, sabe... não adianta não... porque do outro eu tomei a cartela toda... quando eu fui ver... foi logo depois do resguardo; - (...) Nós usava, ela usava remédio(...) o remédio prejudicava e tava dando uma série de problemas. Ela procurou o médico adequado e comprovou que era o remédio. Então decidi (pela vasectomia).

Estudos $^{(7)}$ em várias partes do mundo têm descoberto que a atitude do parceiro influencia muito na duração e continuidade do uso de algum método por parte das mulheres. Esses estudos sinalizaram que, para as mulheres que buscam o contraceptivo oral acompanhadas dos parceiros, a continuidade e eficácia do método eram maiores em comparação com as que iam ao serviço sozinhas. 
b) Dispositivo Intra-Uterino

Verificamos que apesar do aumento da procura e interesse pelo DIU, ele ainda é pouco aceito pelos casais, em decorrência dos mitos e tabus que permeiam o imaginário de homens e mulheres. Ambos relatam medo de uma gravidez com o DIU em uso. Além disso as mulheres referem-se às complicações clínicas e reações adversas provocadas pelo seu uso, como cólicas e aumento do sangramento menstrual, enquanto o homem menciona uma maior preocupação para os possíveis danos físicos que o DIU possa causarIhe.

Os seguintes trechos de discurso nos mostram algumas dessas dificuldades: - (...) aí eu pus o DIU, depois dele eu pus o DIU, aío DIU dele... me deu hemorragia... foi 20 dias de sangramento direto, aí eu tive que tirar o DIU; - (...) O DIU eu nunca tive vontade de colocar porque ele é abortivo; - (...) a minha esposa usou o DIU, depois da segunda gravidez. A partir momento que ela começou a usar o DIU, a gente tava tranqüilo, tinha relações sexuais tranquilas, sem medo de engravidar. Após algum tempo ela passou a ter um corrimento vaginal, então ela retirou 0 DIU.

c) Condom

Este é, provavelmente, um dos mais antigos métodos contraceptivos de uso masculino. Entretanto, a sua aceitabilidade entre os homens pesquisados ainda é pequena. São as mulheres que procuram os serviços de saúde para buscar preservativo para seus companheiros. Elas relataram, com grande ênfase, a nãoaceitação do uso do preservativo pelos homens, que dizem ser este um acessório que os incomoda e reduz a sensibilidade no ato sexual.

Vejamos alguns trechos de discursos que nos mostram essa perspectiva: - (...) tem camisinha também, mas meu esposo não gosta de usar a camisinha, ele usa igual quando eu tava de resguardo de outras crianças, ele usava, mas agora desse aqui ele não quer usar; eu falei assim que enquanto eu não fizer a ligadura nos não vai fazer sexo não, porque do jeito que eu pego filho, não pode facilitar não. Se for fazer tem que usar camisinha. Meu marido fala que não gosta de usar camisinha porque não sente prazer, machuca, acho mais é que é machismo mesmo; - (...) eu também usar camisinha ou diafragma, acho que não é conveniente, não é conveniente, não é agradável pro casal.

A não-aceitação do uso do condom é visto pela mulher como uma atitude do homem de não participar e colaborar na contracepção. Em muitas situações, pudemos verificar, pela fala das mulheres, sentimentos de opressão, autoridade, poder e domínio do homem sobre a mulher. Algumas vezes, elas relatam momentos em que sentem dificuldade em manifestar seus desejos e suas necessidades e revelam com certa tristeza a carência de solidariedade de seus companheiros.
- (...) aí, ela (médica) falou que ia receitar camisinha pro meu marido, aí eu falei assim: não adianta nem receitar porque ele não usa. Eu fui franca com ela, porque assim né, se ele usasse, tinha evitado mais uns tempo pra mim num arrumar, porque a médica avisou pra mim, que as minha gravidez são de alto risco. Eu cheguei avisei, falei, né; ele falou: se for pra usar camisinha, acabou.

d) Método de Ogino-Knauss

Este é considerado um método comportamental cuja eficácia depende da colaboração dos parceiros envolvidos, do conhecimento da fisiologia do corpo feminino e da interação entre os parceiros. Observamos que tanto homens quanto mulheres concordam que é um método que, em suas experiências, tem se mostrado falho, especialmente por requerer uma disciplinada e rigorosa regularidade nas relações sexuais, o que gera, além de dificuldades, desestímulo.

\section{A busca por métodos definitivos}

A busca pelo método definitivo tem significados distintos para homens e mulheres. Na experiência das mulheres, a esterilização cirúrgica representa o método mais seguro e eficaz para limitar o número de filhos, após terem vivenciado o uso de métodos contraceptivos temporários, principalmente a pílula. 0 apelo para o método cirúrgico representa uma indisposição em continuar assumindo a contracepção de maneira solitária, sem a colaboração do companheiro. Na perspectiva das mulheres, a laqueadura, como recurso definitivo, representa a única forma de alcançar o objetivo de limitar o número de filhos e livrar-se do temor de uma gravidez indesejada. Além disso, a laqueadura possibilita-lhes o rompimento com sua vida reprodutiva, mas não a sexual, o que lhes permite viver como um ser de novas possibilidades. Uma destas é a de um ser-trabalhador, podendo fazer parte do mundo público, contribuindo para a renda da família e para uma melhor qualidade de vida.

Vejamos alguns fragmentos de discurso: - (...) eu, prá mim é só a ligadura mesmo, porque os outros métodos eu usei né... mais num valeu nada". (...) agora, eu vou trabalhar e ajudar ele, igual número de filhos, né, eu tenho suficiente, né.

$\mathrm{Na}$ experiência dos homens a busca pela vasectomia e conseqüentemente, o encerramento da paternidade significa, fundamentalmente, a busca de liberdade existencial.

Pudemos observar que ambos solicitam o método contraceptivo definitivo como solução para limitar o número de filhos. Ambos concordam que as restrições impostas pelas condições econômicas são fatores que justificam a limitação do número de filhos. 
Vejamos o trecho de um discurso: - (...) eu não quero ter mais. Não quero. Eu quero ter paz. Eu quero ter a liberdade de poder dar uma condição pra ela (filha), mas também ter a minha liberdade, ter o meu lazer. Eu acho que a vida não se resume só em trabalho, não se resume só em familia, resume também num momento que você tem que separar pra você. Eu quero ter essa liberdade, eu não quero arriscar por causa disso.

Os significados são diferentes para ambos. Enquanto para a mulher a laqueadura significa a possibilidade de participar de uma atividade econômica e, conseqüentemente ser reconhecida na sociedade produtiva, para o homem, que naturalmente já está inserido nessa sociedade, o encerramento da paternidade significa liberdade, acesso ao lazer e convívio com os filhos.

A pílula e a esterilização são os métodos contraceptivos mais utilizados pelos casais e estão fortemente dissociados do ato sexual, não requerendo, portanto, uma cumplicidade de ambos. Desta forma, é a mulher quem ainda arca, sobremaneira, com a responsabilidade da contracepção e, na maioria das vezes, sem a participação do homem.

\section{Sexualidade e Contracepção}

Tanto para homens quanto para mulheres, separar a sexualidade da concepção foi um aspecto evidenciado em suas falas, entretanto, a maneira como cada um vivencia esse aspecto difere. As mulheres que buscam um método definitivo vivenciam ambigüidades, como culpas e angústias - de um lado, por negarem a função reprodutora que lhes é peculiar e, de outro, por poderem vivenciar plenamente a sua sexualidade, ou, ainda, poderem submeter-se às exigências de seus parceiros. Vejamos trechos do depoimento de duas mulheres: - (...) a gente nem sente prazer direito, né, porque a gente fica com aquela cabeça, pensando que vai engravidar, - (...) então eu quero a ligação, que eu possa garanti...que eu vou fica por conta dele, porque ele tá danado mesmo.

Às vezes o desejo de livrar-se uma gravidez não desejada é tão forte que a mulher abre mão da sexualidade e enfrenta 0 fantasma da frigidez.

Vejamos o seguinte fragmento de discurso: - (...) eu quero ligar; eles fala que...que mulher ligada num... num fica a gosto do marido, esfria muito, mas né ...fica fria, o marido vai paquerar outra, vai largar ela de lado; eu prefiro ficar só com meus filhos só, do que ficar enchendo a casa, depois quem vai sofrer é a gente mesmo pra poder dá conta deles.

Segundo a concepção merleaupontiana, "a frigidez quase nunca está ligada a condições anatômicas ou fisiológicas, mas que ela traduz, a maior parte das vezes, a recusa ao orgasmo, à condição feminina ou à condição de ser sexuado, e este, por sua vez, a recusa ao parceiro sexual e ao destino que ele representa"(8).

Para os homens a impossibilidade de vivenciar seu estarcom na intimidade, mantendo um relacionamento sexual de prazer, de satisfação e com regular freqüência com suas companheiras, gera sentimentos de infelicidade e frustração, pois não experimentam de forma plena sua sexualidade.

Nesse sentido, o esvaziamento das opções dos métodos contraceptivos impede os homens de viverem sua sexualidade livre de tensões e temores de uma gravidez não-desejada. Os discursos a seguir apontam essa interferência no relacionamento do casal: (...) ela ganhou menino em novembro, desde novembro para cá que eu não mantenho relações. 0 médico proibiu ela de tomar remédio, e na época eu pelejei pra arrumar uma operação pra ela, sem êxito; - (...) e a gente não tá tendo relação, é outro problema grave(...) não tem condição de você tomá um comprimido que você não tem desejo, não tem vontade, vomita. Pra você tê uma relação no mês, mesmo assim um pouco forçado, pressionando a pessoa. Eu acho que não vale a pena(...) 0 relacionamento do casal dá muita energia pra gente, descarrega muita coisa fora, como isto não tá acontecendo, como eu também não vou arriscá uma tabela.

Separar o prazer da reprodução é apenas um passo para uma vivência sexual com mais qualidade; entretanto a complexidade das relações humanas e, em especial, da vida sexual, não se resolveriam só por uma contracepção eficaz.

Podemos dizer que a vida sexual/genital do ser humano se manifesta na vida total do sujeito, interferindo e influenciando no seu relacionamento com seu mundo, ou seja, com seus parceiros, filhos, trabalho e com eles próprios.

\section{A participação masculina no planejamento familiar: uma visão feminina}

Partindo-se da premissa de que a concepção é a resultante da interação sexual entre homem e mulher, espera-se que a contracepção seja também um fenômeno, por sua natureza, resultante da conjugação de esforços dos parceiros igualmente envolvidos nessa relação. Entretanto, as mulheres relatam com a maior ênfase a pouca participação dos homens na contracepção.

Os discursos das mulheres mostram-nos quais são os métodos que solicitam a participação do homem, evidenciando, entretanto, a negação desses métodos pelos companheiros, que se recusam a colaborar em uma prática que deveria ser compartilhada pelo casal. Atitudes de dominação e não colaboração podem ser vistas nos seguintes discursos: - (...) porque assim, né... se ele usasse, tinha evitado mais uns tempo pra mim num arrumar(...) ele falou assim: se for pra usar camisinha, acabou(...) apesar que esses homens... a gente tem uns homens ignorantes. 0 meu marido... se for pra ele evitar de camisinha, ela não evita, não; - (...) aí... eu peguei e conversei com meu marido, ele falou: ah! camisinha eu não vou usar não, porque eu não gosto de usar aquilo.

A vasectomia também não é aceita pelos homens. Podemos observar nos discursos abaixo: - (...) eu pedi pra ele fazer a vasectomia ele não quis, ele não aceitou, não; então, eu não posso ter mais não, chega; - (...)"eu preferia que meu marido fizesse vasectomia né, mas eu 
acho que ele nem conhece, e a gente nem conversou sobre o assunto. Pelo que eu conheço dele, eu acho que ele não vai querer não, ele é muito machista.

As falas das mulheres mostram, de um lado, a nãocolaboração do companheiro no que ser refere ao uso do preservativo e à vasectomia e, de outro, a aceitação e incentivo para que suas mulheres mutilem seus corpos para livrarem-se de uma problemática que, apesar de envolver ambos, parece ser encarada por eles como sendo de âmbito exclusivo das mulheres.

Vejamos as unidades de significado que mostram isso: (...) conversei com ele; aí, ele falou: ah! é, isso é bom mesmo;(...) eu voltei conversei com ela (a funcionária) e falei que ele (o marido) tinha autorizado, que nós tinha conversado lá, que ele tinha autorizado pra mim ligar.

\section{A visão dos homens acerca da sua participação no planejamento familiar}

A maioria dos discursos dos homens aponta a sua participação no planejamento familiar como conseqüência de sua preocupação com as condições financeiras para cuidar da família. Essa preocupação é decorrente do papel que a sociedade atribui ao homem, como o principal provedor da família. Podemos verificar nos discursos que se seguem: - (...) no meu ponto de vista, planejar uma família, no inicio eu tenho que ganhar bem, ganhar mais ou menos pra mim manter ela e ele, a gente devia planejar primeiro pra gente pensar em ter filho; - (...) significa dá apoio aos filhos que a gente tem, na educação, no meio que a gente vive, nas coisas que tá ao redor da gente, hoje um filho precisa de uma boa escola, precisa de uma boa educação, uma boa casa, quer ter um apoio moral, principalmente dos pais, a gente tem que tá preparado tanto psicologicamente, como financeiramente.

Embora a participação do homem na reprodução seja limitada, o significado psicológico da paternidade para ele é muito importante, mas manifesta-se talvez de formas diferentes e pode variar de acordo com os diversos padrões culturais e grupos sociais de uma mesma sociedade ${ }^{(9)}$. Assim, a paternidade pode ser positiva para o homem, por um lado, mas também pode significar aumento da responsabilidade financeira e uma preocupação em fornecer à sua família melhor qualidade de vida. 0 homem reflete esse estado de preocupação em seu mundo - vida, ou como ser - no - mundo, que vive um horizonte de responsabilidades e deveres para com os filhos e com a companheira, e, ao mesmo tempo, um horizonte do seu próprio mundo interno de compromissos e inseguranças.

Se, de um lado, percebemos que a questão financeira está em evidência e ainda em acordo com o modelo patriarcal, por outro, esse modelo começa a ser questionado pelas mulheres e pelos próprios homens. Pudemos perceber uma nova tendência que começa a ser delineada a partir da fala dos homens, apontando para uma preocupação com a sua maior participação na vida familiar, doméstica e com suas companheiras.

Os seguintes trechos de discursos revelam essa interpretação: - (...) é ajudar a esposa e ajudar a gente também. Quando dá certo com a mulher, conversando sobre o dia-a-dia, os problemas(...) eu sempre ajudei muito em casa, quando ela ganhava, eu dava mamadeira, trocava fralda. Nós conversa muito; - (...) o planejamento familiar, ele acontece a partir daí, porque o casal entra em consenso e os dois participam do planejamento familiar, não basta só a mulher querer e o homem não querer, tem que ter os dois querendo.

A cultura patriarcal em que vivemos colocou a mulher no âmbito da maternidade, do lar, e das tarefas internas da família. 0 mundo externo foi considerado de âmbito masculino. Percebemos, no entanto, que as mulheres entrevistadas neste estudo estão questionando e solicitando a participação do homem na vida familiar, uma vez que elas entraram no mundo público e têm assumido uma dupla jornada de trabalho.

À medida que a mulher tem participado mais do mundo público, o homem vem sendo solicitado a participar do mundo familiar, ajudando a companheira nos trabalhos domésticos e no cuidado com os filhos.

Nossos estudos ${ }^{(4-5)}$ permitiram verificar a existência de um conflito tensional de responsabilidades masculina e feminina no campo do planejamento familiar, contracepção e criação de filhos. 0 conflito dessas tensões impulsiona homens e mulheres para uma nova situação existencial: a da redefinição dessas responsabilidades, que se dá a partir do espaço da coexistência e do compartilhamento.

Dessa forma, um novo homem está emergindo, embora muito lentamente. Paralelo a seu lado racional e objetivo, surge um espaço no lado emocional, essencial no desempenho da vivência familiar. E, apesar de toda a dimensão biológica reprodutiva ser ainda encarada, fundamentalmente, como de âmbito feminino, percebemos que os homens desejam participar mais do planejamento familiar.

\section{A condição socioeconômica e o número de filhos}

Esse aspecto emergiu com bastante ênfase nos depoimentos tanto de homens quanto de mulheres. A questão econômica mostrou-se como fator determinante do número de filhos.

As dificuldades materiais que se referem a moradia, educação, alimentação e cuidados médicos são um forte incentivo para que os homens e mulheres pesquisados queiram limitar 0 número de filhos de modo a oferecer-lhes uma melhor qualidade de vida. 
Vejamos alguns fragmentos de discursos que nos mostram essa situação: - (...) e outra que não tá tendo jeito nem de vesti eles direito. Igual nos que trabalha na fazenda, lá; ganha pouco de mais, né. Eles estuda... o material também tá caro demais. Eu vou inteirar 3 na escola, aí eu fico com dó deles, porque eles vive reclamando que eles vai mal arrumado na escola; a menina até chora, porque os meninos faz pouco caso dela, chama ela de mendiga... aí fico com dó dela, porque ela chega chorando da escola... ali; eu falei assim: então eu vou arrumar mais pouco. Ligadura... até tá numa boa quantia já né. Aí eu tendo os 5, eu vou tratar deles mais melhor também...calça eles melhor, - (...) eu falei, não é que a gente tá numa época assim de querer encher a casa de filho. Num ter uma condição melhor de dá pro filho da gente. Porque de repente o emprego amanhã não tem. E vem a saúde das crianças, o alimento, o lugar onde vai colocar ele.

As dificuldades econômicas são fatores que conspiram contra a família numerosa. 0 número ideal de filhos parece estar diretamente relacionado às metas e planos traçados pelo casal no que se refere à sobrevivência e segurança.

\section{CONSIDERAÇÕES FINAIS}

0 reexame dos resultados dos nossos estudos ${ }^{(4-5)}$ mostra um movimento de transformação que aponta para modificações que estão ocorrendo nos papéis que homens e mulheres ocupam em relação a reprodução, sexualidade e vida familiar.

Verificamos, de um lado, que a mulher está solicitando que os homens assumam sua parcela de responsabilidade na contracepção, na criação e educação dos filhos e nas tarefas domésticas. Por outro, verificamos também que os homens

\section{REFERÊNCIAS BIBLIOGRAFICAS}

1. Carvalho JAM, Wong LR. La Transición de la fecundidad en el Brasil: causas e concecuencias [trabalho apresentado no Seminário sobre Transición de la Fecundidad en América Latina; 1990, Buenos Aires]. 2. Sociedade Civil Bem-Estar Familiar no Brasil (BEMFAM). Comportamento reprodutivo e Sexual da População Masculina. Rio de Janeiro (RJ): BEMFAM; 1999.

3. Schiavo MR. Síndrome do Machismo e Planejamento Familiar na América Latina. Série de publicações técnicas. Rio de Janeiro (RJ): Sociedade Civil Bem-Estar Familiar no Brasil; 1987 nº 11.

4. Galastro EP. Concepção do planejamento familiar na visão dos homens e dos profissionais que vivenciam. [dissertação]. Belo Horizonte (MG): Escola de Enfermagem da Universidade Federal de Minas Gerais; 1997. mostraram disposição em assumir essas responsabilidades frente às novas demandas.

Essa nova situação existencial, produto da relação tensional entre papéis de homens e mulheres, cria um movimento de transcendência, contribuindo para o redimensionamento desses papéis.

0 reexame dos resultados de nossas pesquisas mostra que parece haver um certo desencontro entre essa nova forma de compreender as responsabilidades de homens e mulheres, relacionadas ao controle da fecundidade, e a forma como os serviços de saúde reprodutiva estão organizados. Essa organização reforça que é ainda a mulher a principal responsável pelas questões reprodutivas, uma vez que a assistência está voltada, predominantemente, para ela, não oferecendo oportunidades de participação masculina.

A partir dessa perspectiva, propomos que a instituição ofereça: [a] serviços convenientes para homens; [b] programas educativos em saúde reprodutiva e sexual envolvendo ambos os sexos; [c] promoção de métodos masculinos. Como consequência, poderemos ter homens mais participativos e responsáveis.

Compreendemos que, dessa forma, os serviços de saúde poderão colaborar para que os homens assumam sua parcela de responsabilidade no comportamento reprodutivo e sexual. Entendemos, entretanto, que a igualdade de responsabilidades nesse campo só será plenamente alcançada quando também ocorrer igualdade de gênero em todas as outras esferas da vida - trabalho, família, criação dos filhos, planejamento familiar - dentre outras.

Cremos ser essa a nossa contribuição para a construção de uma assistência à saúde reprodutiva centrada na perspectiva do usuário.

5. Marcolino C. Trajetória da mulher em direção a esterilização cirúrgica feminina: um estudo fenomenológico [dissertação]. São Paulo (SP): Faculdade de Saúde Pública da Universidade de São Paulo; 1994.

6. Breilh J. El genero entrefuegos: inequidade y esperanza. Quito: Paz y Miño; 1996.

7. Os homens: novo enfoque para os programas de planejamento familiar. Popul Rep Ser J 1987 dezembro; 33:1-36.

8. Merleau-Ponty M. Fenomenologia da Percepção. São Paulo (SP): Freitas Bastos; 1971.

9. Werebe MJG. Sexualidade e população, crescimento demográfico e planejamento familiar. Ciência e Cultura 1985 novembro; 37(11):1805-14. 